\title{
The Efficient Assessment of Self-Esteem: Proposing the Brief Rosenberg Self-Esteem Scale
}

\author{
Renan P. Monteiro ${ }^{1} \cdot$ Gabriel Lins de Holanda Coelho ${ }^{2}$ (D) Paul H. P. Hanel ${ }^{3}$. \\ Emerson Diógenes de Medeiros ${ }^{4}$. Phillip Dyamond Gomes da Silva ${ }^{1}$
}

Received: 31 July 2020 / Accepted: 28 February 2021 / Published online: 27 April 2021

(C) The Author(s) 2021

\begin{abstract}
Self-esteem is defined as sense of self-worth and self-respect, being crucial for understanding people's well-being and success. It is one of the most studied constructs in the social sciences, with the Rosenberg Self-Esteem Scale (RSES) being the most used measure. Across four studies $(N=1450)$, we tested the psychometric parameters of an abbreviated version of the RSES. Through Item Response Theory, the five best items were selected to form the unidimensional Brief Rosenberg Self-Esteem Scale (BRSES), a reliable and valid measure of self-esteem, which is invariant across age groups and gender. In addition, both RSES and B-RSES correlated very similarly with the Big Five Personality Factors. Also, the B-RSES was strongly correlated with three other short measures of self-esteem, besides being more strongly associated with a range of variables such as conscientiousness and self-competence in comparison to the other three short scales. Together, the B-RSES is especially useful in research that requires rapid evaluation and the use of multiple variables.
\end{abstract}

Keywords Self-esteem $\cdot$ Measure $\cdot$ Psychometrics $\cdot$ Validity $\cdot$ Personality

Renan P. Monteiro

renanpmonteiro@gmail.com

$\triangle$ Gabriel Lins de Holanda Coelho

linshc@gmail.com

$\triangle$ Paul H. P. Hanel

p.hanel@essex.ac.uk

1 Department of Psychology, Federal University of Mato Grosso, Fernando Corrêa da Costa Avenue, 2367, Boa Esperança, Cuiabá, MT 78060-900, Brazil

2 School of Applied Psychology, University College Cork, Cork, Ireland

3 Department of Psychology, University of Essex, Colchester CO4 3SQ, UK

4 Department of Psychology, Federal University of Delta do Parnaíba, Parnaíba, PI 64202-020, Brazil 


\section{Introduction}

Self-esteem is the individual's sense of self-worth and self-respect (García et al., 2019; Gnambs et al., 2018) and is an evaluative component of the self-concept (Hutz \& Zanon, 2011). Self-esteem correlates positively with well-being (Freire \& Tavares, 2011), life satisfaction (Diener \& Diener, 1995), positive affects (Segabinazi et al., 2012), and engagement and satisfaction with one's work (Salmela-Aro \& Nurmi, 2007). On the other hand, self-esteem is negatively correlated with negative affects (Segabinazi et al., 2012), depression and anxiety (Sowislo \& Orth, 2013; Steiger et al., 2014), and risk for obesity (Iannaccone et al., 2016).

Together, self-esteem is crucial for understanding people's well-being and success. It is therefore not surprising that it attracted a lot of attention from researchers. Indeed, Rosenberg's (1965) book in which the Rosenberg's SelfEsteem Scale (RSES) has been proposed, has been cited over 40,000 times according to Google Scholar (as in February 2020), making it the most widely used instrument to measure self-esteem: Almost 50\% of empirical studies on selfesteem published in major scientific journals used the RSES (Donnellan et al., 2015). The RSES is unidimensional and consists of 10 statements that are related to one's feelings of self-esteem, self-competence, and self-acceptance (Hutz \& Zanon, 2011). The factor structure and reliability of the RSES has been supported in many countries, including Argentina (Góngora \& Casullo, 2009), Brazil (Lima \& Souza, 2019; Sbicigo et al., 2010), Japan (Mimura \& Griffiths, 2007), and Spain (Martín-Albo et al., 2007). Further, in a study with 16,998 participants from 53 nations, Schmitt and Allik (2005) found evidence of the cross-cultural unidimensionality of the RSES.

Although the findings by Schmitt and Allik (2005) support the one-dimensional structure of the RSES, a two-factor structure is commonly reported in the literature that groups positive and negative items into different dimensions (Gnambs et al., 2018). Thus, the structure can be explained by the way the items are phrased, either with positive or negative wording. This methodological effect results in a spurious factor (Valentini, 2017). Nevertheless, negatively worded items are important because they increase the validity of a scale (Clifton, 2020).

In a cross-cultural meta-analysis of 113 independent samples $(N=140,671)$, Gnambs et al. (2018) found that a bifactor model, represented by a general factor (self-esteem) and two specific factors (positive and negative), showed the best fit. Gnambs and Schroeders (2017) argued that these factors emerge because of lower cognitive abilities (i.e., reading and reasoning), resulting in difficulties to understand negative items. However, the variance of the items is better explained by the general factor than its specific factors, supporting the unidimensionality of the RSES (Gnambs et al., 2018).

Together, this research shows that the RSES is a reliable unidimensional measure of self-esteem. However, previous research often found that unidimensional measures with more than around six items can be shortened to 5-6 items without losing information (e.g., Appel et al., 2012; Bakker \& Lelkes, 2018; Coelho et al., 2020). In the present research, we test using exploratory and confirmatory factor analyses as well as Item Response Theory whether we can shorten the 10-item RSES to a briefer measure of comparable reliability and validity. 


\section{The Importance of Short Measures}

Brief instruments are particularly useful in survey studies, in which the objective is not to diagnose or make decisions at the individual level, but to make inferences about the population (Rammstedt \& Beierlein, 2014). Therefore, measures such as the RSES that have ten items disposed in a single factor, might be unnecessarily long.

The length of scales can be one of the main obstacles to recruit participants, especially when a survey includes several scales and with low or no funding to compensate participants. Long scales may result in lower response rate, because they cause fatigue and boredom among participants, which additionally may compromise the quality of the responses (Coelho et al., 2020; Rammstedt \& Beierlein, 2014). Also, psychological research is increasing in complexity, testing explicative models with multiple variables (e.g., Structural Equation Modelling), which often requires collecting many measures in a large sample. Therefore, the development of short and psychometrically suitable measures is crucial (Rammstedt \& Beierlein, 2014; Ziegler et al., 2014).

Thus, in recent years more and more scales have been reduced to short measures which assess clinical (e.g., two-item Generalized Anxiety Disorder Scale; REF) and non-clinical (e.g., six-item Need for Cognition Scale; Coelho et al., 2020) constructs. Importantly, these shorter versions are typically as reliable and valid as the lengthier scales from which they were derived from (e.g., they predicted other variables equally well; Kemper et al., 2019; Konstabel et al., 2017). It is therefore not surprising that short self-esteem scales have already been proposed. The first attempt to reduce the item number of the RSES was carried out by Robins et al. (2001). The authors argued that the Single-Item Self-Esteem (SISE) scale, "I have high self-esteem", can replace the RSES. This was because the SISE and the RSES correlated highly, $r=.75$, and had a similar pattern of correlations with the Big Five personality traits. For instance, both measures correlated positively with extraversion and conscientiousness, and negatively with neuroticism. Nevertheless, Donnellan et al. (2015) pointed out caveats when using SISE, because of its lower test-retest reliability, greater susceptibility to acquiescence bias, and because psychometric parameters are not as well explored as for the RSES.

Another short measure is the recently proposed Lifespan Self-Esteem Scale (LSES; Harris et al., 2018). The scale is composed of four items that load on one factor. While the LSES shows evidence of convergent validity and good reliability, its content validity is low, because its items cover only feelings of self-acceptance. Also, the items are repetitive (i.e., "How do you feel about yourself?" is equal to "When you think about yourself, how do you feel?", and "How do you feel about the kind of person you are?" is equal to "How do you feel about the way you are?"). Furthermore, the wording of the items can lead to acquiescence bias, resulting in an overestimation of positive relations and underestimation of negative relations of the LSES with external variables (Valentini \& Hauck Filho, 2020). Moreover, global self-esteem consists of selfcompetence (i.e., feeling confident, capable, effective) and self-acceptance (i.e., feeling good about yourself, socially important; Schmitt \& Allik, 2005). Only the latter subcomponent is covered by the LSES. We explicitly test this predicting in Study 4.

One alternative measure which covers both subcomponents of self-esteem is the unidimensional Global Self-Esteem Scale (GSES; Rajlic et al., 2019). The convergent validity is good: It correlates strongly with the RSES $(r=.72)$. Nevertheless, the GSES shares one limitations with the SISE and the LSES: All items are positively worded. 
Thus, the scale does not control for acquiescence bias. This is an issue because positive self-assessment is culturally universal (Schmitt \& Allik, 2005). Measures that do not have negative items and do not control for acquiescence can inflate this positive assessment, generating an effect resulting from the method rather than the construct. Indeed, people endorse more the positive items of the RSES (DiStefano et al., 2012) and the GSES showed stronger correlations with the positive items of the RSES $(r=.75 ; p<.001)$ than with the negative items $(r=.57 ; p<.001)$, which suggests an agreement bias for the positive items.

The 16-item Self-Liking and Self-Competence Scale (Tafarodi \& Swann Jr., 2001) which measures both subcomponents of self-esteem, overcomes the acquiescence bias because it includes positive and negative items. Although designed as two-dimensional, some authors use the total score of this scale as they are strongly related with each other (Donnellan et al., 2015). However, we decided to test whether the RSES can be reduced to a shorter measure instead of the Self-Liking and Self-Competence Scale, because it is rarely used in the literature (Donnellan et al., 2015), the RSES covers the same two components (Sinclair et al., 2010), and because of the wide spread popularity of the RSES.

Together, while a 10-item version of the RSES is likely unnecessarily long, a 1-item measure of self-esteem is likely too short to measure self-esteem reliable and valid (cf. also Bakker \& Lelkes, 2018). Moreover, Gray-Little et al. (1997) analyzed the RSES using IRT and showed that some items are unable to differentiate between participants, thus providing little additional information, or do not measure self-esteem very well. The authors concluded that a short version of the RSES would be beneficial, but so far this suggestion has not been empirically followed-up. Furthermore, the LSES and GSES present only positive items are is therefore more susceptible to acquiescence bias. Harris et al. (2018) point out that several researchers use shorter versions of the RSES, but without providing a plausible item selection justification. In the present research, we aim to fill this gap.

\section{The Present Research}

The present research tests whether the RSES can be shortened (Study 1), whether the factor structure of the brief-RSES is unidimensional (Study 2), is correlated to a similar extent with the Big Five personality traits as the original RSES (Study 3), and provides divergent validity of other self-esteem measures (Study 4). Based on previous findings (e.g., Pimentel et al., 2018; Robins et al., 2001; Schmitt \& Allik, 2005), we expect positive associations between B-RSES and emotional stability, conscientiousness, and openness.

\section{Study 1}

\section{Method}

Participants and Procedure Participants were 450 individuals from the general population $\left(M_{\text {age }}=26.08 ; S D=10.23\right.$, range $\left.=18-70\right)$, mostly women $(72 \%)$, single $(76.9 \%)$, from middle class $(49.1 \%)$, and with incomplete higher education $(44.2 \%)$. Participants were recruited through social media (e.g., Facebook) and completed an online survey. All participants provided informed consent, prior to completing the survey. 


\section{Measures}

Rosenberg Self-Esteem Scale (Rosenberg, 1965). We used the 10-item version translated to Portuguese by Hutz (2000) and validated for Brazil by Sbicigo et al. (2010). Example items include "On the whole, I am satisfied with myself" and "I feel that I have a number of good qualities". Participants indicated their degree of agreement to the items using a 7-point scale (1 - Strongly Disagree; 7 - Strongly Agree).

\section{Data Analysis}

Data were analyzed using Factor (Lorenzo-Seva \& Ferrando, 2013) and R (R Development Core Team, 2020). Factor was used to test the dimensionality of the RSES through Exploratory Factor Analysis (Unweighted Least Squares estimator). We considered the polychoric correlation matrix and used the Hull method (Lorenzo-Seva et al., 2011) to define how many factors to retain. Finally, we used the R-package MIRT (Chalmers, 2012) to obtain the individual parameters of the items through the Graded Response Model (Samejima, 1969).

\section{Results}

The values of Kaiser Meyer Olkin (.90) and Bartlett's sphericity test ([45] $=2589.7$, $p<.001)$ indicated that the polychoric correlation matrix is factorable. The Hull method indicated a single factor solution as the most parsimonious, with eigenvalue of 6.06 and explaining $60 \%$ of the total variance. Specifically, the items presented loadings ranging from .55 (Item 1) to .87 (Item 10), with adequate internal consistency coefficient $(\alpha=.90)$. Further details on the scale structure can be found in Table 1.

Moreover, we assessed the individual parameters of the items via Item Response Theory (Table 1). Overall, the items presented high discrimination $(a=1.17-3.51 ; M=$ 2.25; $S D=0.74$; Baker, 2001), with an average difficulty $\left(\mathrm{b}_{1}-\mathrm{b}_{6}\right)$ of $-0.39(S D=0.87)$. The item that required the lowest level of latent trait was item $1\left(M_{b 1-b 6}=-1.70\right)$, whereas item 2 was the one that required the highest amount of self-esteem $\left(M_{b 1-b 6}=\right.$

Table 1 Factorial loadings and individual parameters of the items of RSES

\begin{tabular}{lllllllll}
\hline & Factorial loadings & $\mathrm{a}$ & $\mathrm{b}_{1}$ & $\mathrm{~b}_{2}$ & $\mathrm{~b}_{3}$ & $\mathrm{~b}_{4}$ & $\mathrm{~b}_{5}$ & $\mathrm{~b}_{6}$ \\
\hline Item 10 & .87 & 3.51 & -1.59 & -1.19 & -0.74 & -0.27 & 0.29 & 0.94 \\
Item 5 & .86 & 3.10 & -0.19 & 0.21 & 0.55 & 0.92 & 1.28 & 1.70 \\
Item 9 & .81 & 2.86 & -1.72 & -1.36 & -0.87 & -0.25 & 0.23 & 1.03 \\
Item 3 & .78 & 2.25 & -0.63 & -0.21 & 0.04 & 0.34 & 0.80 & 1.26 \\
Item 7 & .78 & 2.25 & -2.97 & -2.33 & -1.63 & -0.91 & -0.17 & 0.55 \\
Item 8 & .76 & 2.26 & -2.60 & -1.97 & -1.47 & -0.92 & -0.25 & 0.36 \\
Item 6 & .72 & 1.94 & -0.91 & -0.45 & -0.08 & 0.28 & 0.84 & 1.36 \\
Item 2 & .69 & 1.76 & -0.44 & 0.18 & 0.58 & 0.91 & 1.67 & 2.19 \\
Item 4 & .61 & 1.40 & -2.71 & -2.05 & -1.23 & -0.58 & 0.08 & 0.85 \\
Item 1 & .55 & 1.17 & -3.69 & -3.06 & -2.26 & -1.27 & -0.40 & 0.49 \\
\hline
\end{tabular}


0.85). The information curves (see Fig. 1) of the items shows that items 10, 9, 5, 3, and 8 were most informative ( $\mathrm{I} \theta \geq 1.5$ ), covering a large portion of the latent trait, between -2.60 to 1.70 (Fig. 1). We chose these items to form the Brief Self-Esteem Scale (BRSES), which we further tested through Confirmatory Factor Analysis in Study 2.

\section{Study 2}

\section{Participants, Procedure, and Measures}

Participants were 433 individuals from the general population $(M=23.60 ; S D=7.88$, range $=18-69)$, mostly women $(73.9 \%)$, single $(82.7 \%)$, and with incomplete higher education $(53.3 \%)$. Similar to Study 1, participants were recruited through social media and completed an online survey. Participants completed the Brief Self-Esteem Scale.

\section{Data Analysis}

Data were analyzed using R software (R Development Core Team, 2015). We performed the Confirmatory Factor Analysis (WLSMV estimator) to assess whether the BRSES is unidimensional, using the lavaan package (Rosseel, 2012). The following parameters were used as thresholds (in parentheses the reference values for an appropriate model; Hu \& Bentler, 1999; Kline, 2015): Ratio $\chi^{2 / d f}(<3.0)$, Comparative Fit Index (CFI >.95), Tucker-Lewis Index (TLI > .95), Root MeanSquare Error of Approximation (RMSEA <.06), and Standardized Root Mean Square

\section{Item information trace lines}

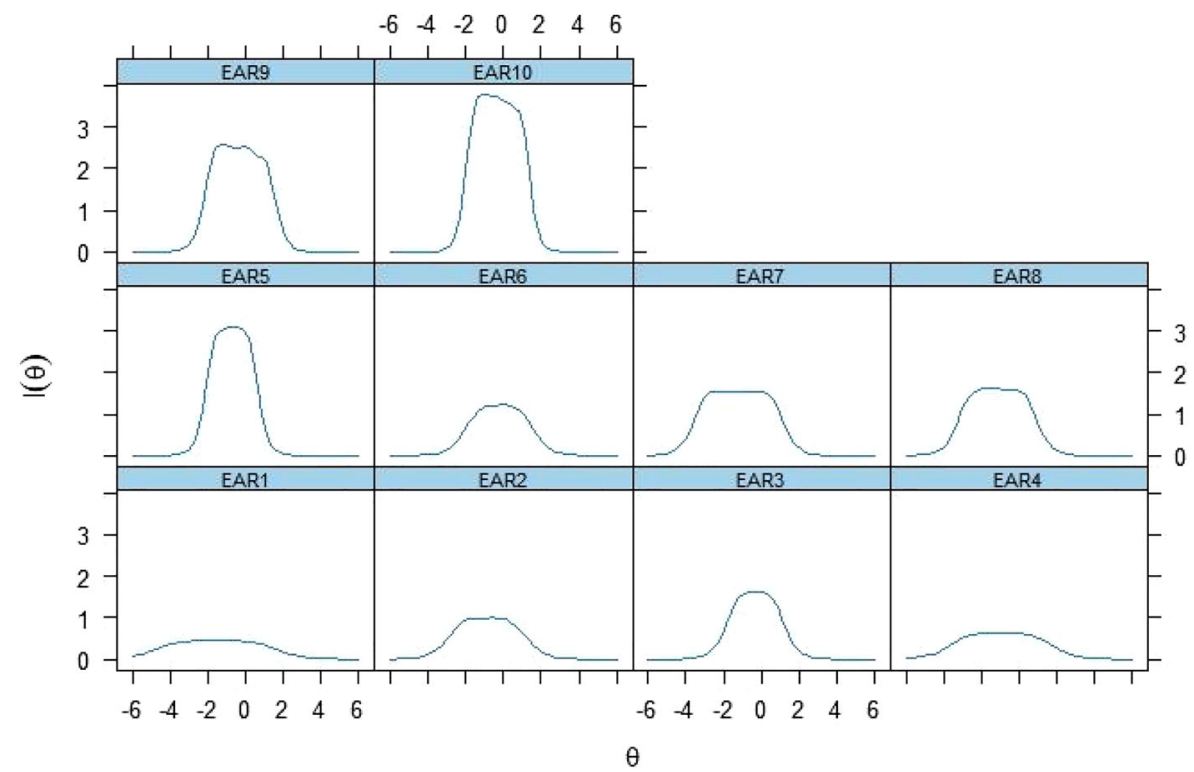

Fig. 1 Test information curves of the RSES 
Residual (SRMR < .08). Additionally, we assessed the individual parameters of the BRSES items, using the Graded Response Model (Samejima, 1969).

\section{Results}

The Confirmatory Factor Analysis showed that the B-RSES fitted the proposed unidimensional model very well, $\chi^{2} / \mathrm{gl}=2.48, \mathrm{CFI}=.99, \mathrm{TLI}=.99, \mathrm{SRMR}=.036, \mathrm{RMSEA}=.059$, $90 \% \mathrm{CI}=.017-.100)$. All items presented statistically significant and non-zero saturations (Table $2 ; \mathrm{z} \neq 0 ; z \mathrm{~s}>1.96, p \mathrm{~s}<.05)$, with a mean lambda of $.78(S D=.06)$, ranging from .71 (Item 8) to .85 (Items 9 and 10). Also, the internal consistency was high $(\alpha=.89)$.

Next, we assessed the individual parameters of the B-RSES items using Item Response Theory. Results indicate a mean discrimination value of $2.81(S D=.87 ; \mathrm{A}=2.13-3.77)$, with an average difficulty of $-.17(S D=.52)$. Item 8 required the lowest level of selfesteem to be fully endorsed, whereas Item 5 required the highest level. Figure 2 shows the psychometric information of the B-RSES and its full version. As can be seen, the reduction does not compromise the psychometric information provided by the measure, covering approximately the same latent trace portion, and being more accurate in the evaluation of people with self-esteem level between -1.0 and 0.0 .

\section{Study 3}

\section{Method}

Participants and Procedure Participants were 347 individuals from the general public $\left(M_{\text {age }}=22.9 ; S D=7.67\right.$, range $\left.=18-59\right)$, mostly women $(61.7 \%)$, single $(86.5 \%)$, and with incomplete higher education $(55.3 \%)$. Participants were recruited through social media and completed an online survey.

\section{Measures}

Rosenberg's (1965) Self-Esteem Scale. The same scale as in Study 1 was used.

Ten-Item Personality Inventory (Gosling et al., 2003). This scale was developed to measure the Big Five personality factors with two items each (Extraversion, Agreeableness, Conscientiousness, Emotional Stability, and Openness to Experience).

Table 2 Factorial loadings and individual parameters of the items of B-RSES

\begin{tabular}{lllllllll}
\hline & Factorial loadings & $\mathrm{a}$ & $\mathrm{b}_{1}$ & $\mathrm{~b}_{2}$ & $\mathrm{~b}_{3}$ & $\mathrm{~b}_{4}$ & $\mathrm{~b}_{5}$ & $\mathrm{~b}_{6}$ \\
\hline Item 10 & .85 & 3.76 & -1.36 & -0.99 & -0.53 & -0.09 & 0.36 & 1.07 \\
Item 9 & .85 & 3.77 & -1.33 & -0.93 & -0.52 & -0.08 & 0.52 & 1.18 \\
Item 5 & .77 & 2.24 & -0.55 & -0.09 & 0.26 & 0.73 & 1.19 & 1.81 \\
Item 3 & .75 & 2.13 & -1.03 & -0.59 & -0.28 & -0.03 & 0.40 & 1.05 \\
Item 8 & .71 & 2.18 & -2.21 & -1.64 & -1.33 & -0.76 & -0.08 & 0.56 \\
\hline
\end{tabular}




\section{Item information trace lines}

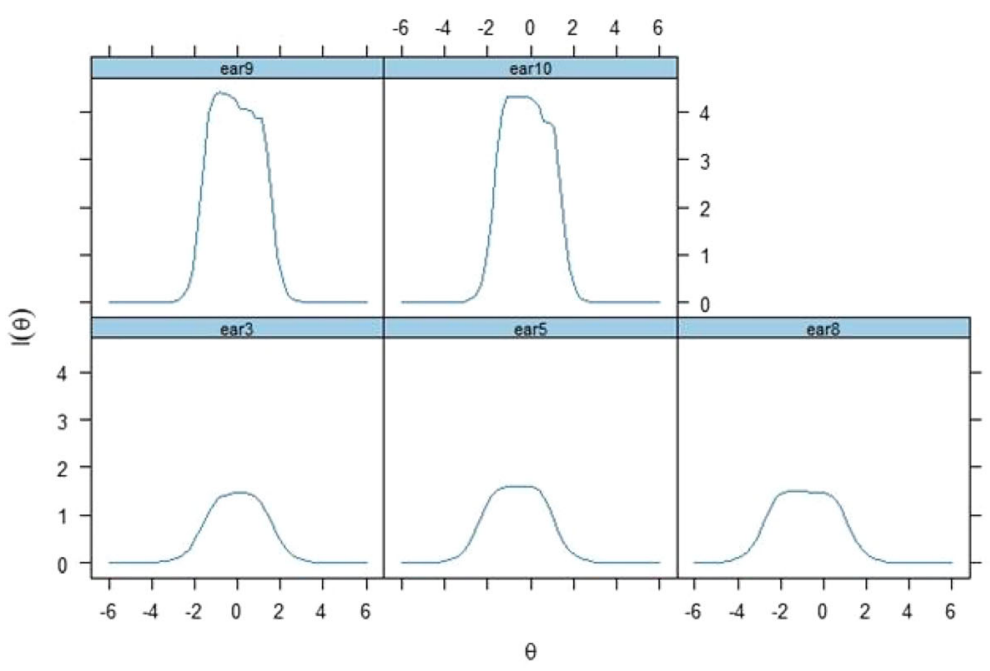

Test Information

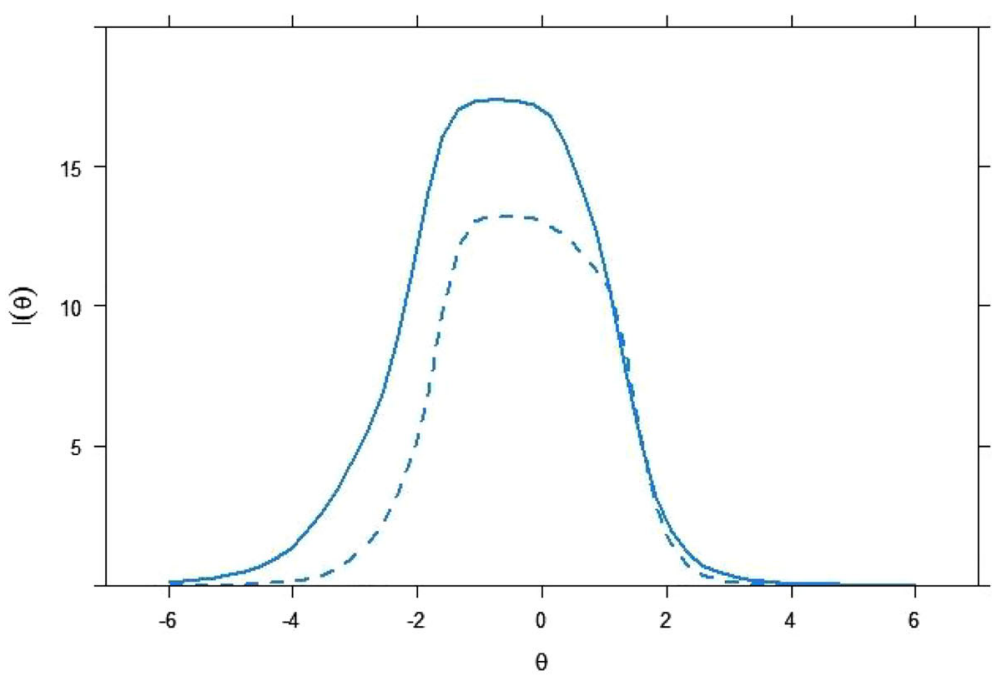

Fig. 2 Test information curves of the B-RSES (dashed line) and RSES

Participants answered the inventory using a seven-point scale (1 - Disagree Strongly; 7 - Agree Strongly). Example characteristics include "Critical, quarrelsome" and "Anxious, easily upset".

\section{Data Analysis}

Data were tabulated and analyzed using SPSS software. Specifically, Pearson's correlation coefficients were calculated to confirm the item-total correlations of B-RSES, as well as to measure convergent validity with the five remaining RSES items, and their associations to the Big Five personality traits. 


\section{Results}

The item-total correlations of B-RSES ranged from .80 (Item 3) to .87 (Item 9). The BRSES strongly correlated with the RSES $(r=.86 ; p<.001)$, and the Big Five Factors (Table 3). Specifically, self-esteem was positively correlated with extraversion (RSES, $r=.25, p<.001$; B-RSES, $r=.24, p<.001$ ), agreeableness (RSES, $r=.22, p<.001$; BRSES, $r=.21, p<.001$ ), conscientiousness (RSES, $r=.45, p<.001$; B-RSES, $r=.44$, $p<.001$ ), openness (RSES, $r=.30, p<.001$; B-RSES, $r=.30, p<.001$ ), and emotional stability (RSES, $r=.55, p<.001$; B-RSES, $r=.55, p<.001$ ). Together, shortening the RSES by $50 \%$ of its items did not affect its reliability remained excellent $(\alpha=.88)$, and the B-RSES showed the same pattern of correlation with Big Five as the RSES.

\section{Study 4}

In Study 4, we tested whether the B-RSES correlates with other self-esteem measures. Crucially, we also tested whether the B-RSES explains variance above and beyond three other short measures of self-esteem, the SISE, GSES, and LSES in openness and conscientiousness. We included openness and conscientiousness because contrary to the SISE and LSES which tap in our understanding more into emotional aspects of selfesteem (i.e., self-acceptance) rather than the cognitive aspects (i.e., self-competence). For example, the LSES asks people only about how they feel about themselves (see discussion above). Indeed, the LSES correlated weaker than the B-RSES with openness $(r \mathrm{~s}=.09$ vs .30$)$ and conscientiousness ( $r \mathrm{~s}=.36$ vs .45 ; see Harris et al., 2018 and Study 3 above). Similarly, we expected that the B-RSES would explain variance beyond the LSES and SISE in self-competence but not in self-liking.

\section{Method}

Participants and Procedure Participants were 220 individuals from the general public $\left(M_{\text {age }}=28.70 ; S D=9.48\right.$, range $\left.=18-64\right)$, mostly women $(81.4 \%)$, single $(60 \%)$, and with incomplete higher education (40\%). Participants were recruited through social media sites and completed an online survey.

Table 3 Convergent validity of the B-RSES

\begin{tabular}{llll}
\hline & RSES & B-RSES & Remaining 5 RSES items \\
\hline Study $3(N=347)$ & & & \\
Openness & $.30^{* *}$ & $.30^{* *}$ & $.29 * *$ \\
Conscientiousness & $.45^{* *}$ & $.44 * *$ & $.43 * *$ \\
Extraversion & $.25 * *$ & $.24 * *$ & $.25 * *$ \\
Agreeableness & $.22^{* *}$ & $.21^{* *}$ & $.21^{* *}$ \\
Emotional Stability & $.55^{* *}$ & $.55^{* *}$ & $.51 * *$ \\
\hline
\end{tabular}

Note. $* p<.05, * * * p<.001$ 


\section{Measures}

Rosenberg's (1965) Self-Esteem Scale. The same items as in Study 1 were used.

The Lifespan Self-Esteem Scale (Harris et al., 2018). The LSES consists of four items (e.g., How do you feel about yourself?). Responses were given on a 5-point scale (1-Really Sad; 5 -Really Happy). In the present study, this measure presented an excellent reliability coefficient (Cronbach's alpha, $\alpha=.94$ ).

Global Self-Esteem Scale (Rajlic et al., 2019). The GSES consists of six items (e.g., I think of myself in positive terms) that assess one general factor of self-esteem (Cronbach's alpha, $\alpha=.92$ ). Participants indicate to what extent they agree with the items, using a 6-point scale (1 - Strongly Disagree; 6 - Strongly Agree).

Self-Liking and Self-Competence Scale (Tafarodi \& Swann Jr., 2001). The SLSCS is composed by 16 items, equally distributed among two factors: self-acceptance (e.g., $I$ am secure in my sense of self-worth; Cronbach's alpha, $\alpha=.93)$ and self-competence (e.g., I am almost always able to accomplish what I try for; Cronbach's alpha, $\alpha=.82$ ). Participants indicate to what extent they agree with the items, using a 5-point scale (1 Strongly Disagree; 5 - Strongly Agree).

Single-Item Self-Esteem (Robins et al., 2001). Participants simply answered to what extent the item "I have high self-esteem" described them, using a 7-point scale (1 - Not very true of me; 7 - Very true of me).

Mini-IPIP (Donnellan et al., 2006). We used measured openness (e.g., Have a vivid imagination; Cronbach's alpha, $\alpha=.53$ ) and conscientiousness (e.g., Like order; Cronbach's alpha, $\alpha=.69)$ items. Participants indicated to what extent the items describe them (1 - Very Inaccurate; 5 - Very Accurate). The internal consistency levels we found are consistent with previous studies (e.g., Baldasaro et al., 2013; Cooper et al., 2010).

\section{Data Analysis}

Data were analyzed using R software (R Development Core Team, 2015) and SPSS. We performed the Confirmatory Factor Analysis (WLSMV estimator) to compare the fit of the B-RSES with the other self-esteem measures. For that, we used the lavaan package (Rosseel, 2012). The following parameters were used as thresholds (in parentheses the reference values for an appropriate model; Hu \& Bentler, 1999; Kline, 2015): Ratio $\chi^{2} / \mathrm{df}(<3.0)$, Comparative Fit Index (CFI $\left.>.95\right)$, Tucker-Lewis Index (TLI > .95), Root Mean-Square Error of Approximation (RMSEA < .06), and Standardized Root Mean Square Residual (SRMR < .08). Pearson's correlation coefficients were calculated to test the convergent validity of B-RSES with the other selfesteem measures.

To test whether the B-RSES explains variance above and beyond the other brief self-esteem scales, we performed a series of hierarchical regressions in which the SISE, LSES, or GSES were entered in a first step and the B-RSES was entered in a second step. The outcomes were conscientiousness, openness, as well as selfcompetence and self-liking of the Self-Liking and Self-Competence Scale. We included the latter two as dependent variables because of our assumption that the B-RSES would be more strongly associated with self-competence than the LSES and SISE. 


\section{Results}

A Confirmatory Factor Analysis again provided support for the unidimensional structure of the B-RSES: $\chi^{2} / \mathrm{df}=1.62, \mathrm{CFI}=.99, \mathrm{TLI}=.98$, SRMR $=.017 . \mathrm{RMSEA}=.053$, $\left.\mathrm{CI}_{90 \%}=.000-.117\right)$. Further CFAs showed that both the $\operatorname{LSES}\left(\chi^{2} / \mathrm{df}=1.36, \mathrm{CFI}=1.00\right.$, $\left.\mathrm{TLI}=.99, \mathrm{SRMR}=.008, \mathrm{RMSEA}=.041, \mathrm{CI}_{90 \%}=.000-.147\right)$, and the GSES $\left(\chi^{2} / \mathrm{df}=\right.$ $\left.1.42, \mathrm{CFI}=.99, \mathrm{TLI}=.98, \mathrm{SRMR}=.019, \mathrm{RMSEA}=.044, \mathrm{CI}_{90 \%}=.000-.094\right)$ were also unidimensional. Finally, we found acceptable fit indices for the two-factor structure of the Self-Liking and Self-Competence Scale $\left(\chi^{2} / \mathrm{df}=1.78, \mathrm{CFI}=.93, \mathrm{TLI}=.92\right.$, $\left.\mathrm{SRMR}=.050, \mathrm{RMSEA}=.062, \mathrm{CI}_{90 \%}=.048-.076\right)$.

Moreover, we assessed the convergent validity of the B-RSES (Table 4). The measure is strongly correlated with Self-Competence $(r=.71 ; p<.001)$, Self-Liking $(r=.85 ; p<.001)$ and the total scores of Lifespan Self-Esteem Scale $(r=.86 ; p<.001)$, Global Self-Esteem Scale $(r=.89 ; p<.001)$, and the SISE $(r=.76 ; p<.001)$.

Finally, hierarchical regressions revealed that the B-RSES explained more variance than the LSES, GSES, and SISE in at least two of the four dependent variables, openness, conscientiousness, self-liking, and self-competence (Table 5). A closer look at the standardized coefficients revealed that the B-RSES was more strongly associated with all four dependent variables than the LSES, more strongly than the SISE associated with self-liking and self-competence, and more strongly than the GSES with openness and conscientiousness. As predicted, the B-RSES was a stronger predictor of self-competence than the LSES and SISE.

\section{Additional Analysis: Measurement Invariance across Age and Gender}

In a final step, we tested whether the B-RSES is invariant across age and gender. Establishing invariance is important because it ensures that people understand the items in a similar way across groups (Davidov et al., 2014). Otherwise it is not possible to meaningfully compare groups (e.g., correlation coefficients or group mean comparisons). It is typically recommended to establish three-levels of invariance: configural,

Table 4 Correlations between all variables included in Study 4

\begin{tabular}{|c|c|c|c|c|c|c|c|c|c|}
\hline & 1 & 2 & 3 & 4 & 5 & 6 & 7 & 8 & 9 \\
\hline \multicolumn{10}{|l|}{ 1) BSES } \\
\hline 2) RSES & $.97 * * *$ & & & & & & & & \\
\hline 3) Remaining 5 RSES items & $.87 * * *$ & $.96 * * *$ & & & & & & & \\
\hline 4) LSES & $.86^{* * *}$ & $.86^{* * *}$ & $.80 * * *$ & & & & & & \\
\hline 5) SISE & $.76^{* * * *}$ & $.76^{* * *}$ & $.70 * * *$ & $.68^{* * * *}$ & & & & & \\
\hline 6) GSES & $.89 * * *$ & $.90 * * *$ & $.85 * * *$ & $.82 * * *$ & $.70 * * *$ & & & & \\
\hline 7) Self-liking & $.85 * * *$ & $.85 * * *$ & $.80 * * *$ & $.82 * * *$ & $.76 * * *$ & $.85 * * *$ & & & \\
\hline 8) Self-competence & $.71 * * *$ & $.75^{* * *}$ & $.75^{* * * *}$ & $.67 * * *$ & $.57 * * *$ & $.75 * * *$ & $.75^{* * *}$ & & \\
\hline 9) Openness & 0.12 & $.14^{*}$ & $.15^{*}$ & 0.04 & $.18^{*}$ & 0.05 & 0.06 & 0.12 & \\
\hline 10) Conscientiousness & $.37 * * *$ & $.37 * * *$ & $.35 * * *$ & $.33 * * *$ & $.30 * * *$ & $.31 * * *$ & $.37 * * *$ & $.37 * * *$ & 0.10 \\
\hline
\end{tabular}

Note. $* p<.05, * * * p<.001$ 
Table 5 Hierarchical regressions: Does the B-RSES explain variance beyond other short measures of selfesteem?

\begin{tabular}{llllllll}
\hline Step 1 & DV & $R^{2}$ & $\Delta R^{2}$ & $\Delta F$ & $d f 1, d f 2$ & $\beta_{1}$ & $\beta_{2}$ \\
\hline LSES & Openness & .028 & .027 & $5.93 *$ & 1,217 & -.23 & $.32 *$ \\
& Conscientiousness & .138 & .032 & $7.96 * *$ & 1,217 & .03 & $.35 * *$ \\
& Self-liking & .756 & .080 & $71.43 * * *$ & 1,217 & $.35 * * *$ & $.55 * * *$ \\
& Self-compentence & .515 & .063 & $28.25 * * *$ & 1,217 & $.25 * *$ & $.49 * * *$ \\
SISE & Openness & .035 & .004 & 0.68 & 1,176 & .10 & .10 \\
& Conscientiousness & .103 & .012 & 2.39 & 1,176 & .17 & .17 \\
& Self-liking & .733 & .158 & $104.40 * * *$ & 1,176 & $.29 * * *$ & $.62 * * *$ \\
& Self-compentence & .476 & .154 & $51.80 * * *$ & 1,176 & .10 & $.61 * * *$ \\
GSES & Openness & .032 & .030 & $6.60 *$ & 1,216 & $-.29 *$ & $.38^{*} *$ \\
& Conscientiousness & .136 & .020 & $5.02 *$ & 1,216 & .06 & $.31 *$ \\
& Self-liking & .762 & .043 & $39.10 * * *$ & 1,216 & $.44 * * *$ & $.46 * * *$ \\
& Self-compentence & .571 & .005 & 2.69 & 1,216 & $.61 * * *$ & .16 \\
\hline
\end{tabular}

Note. The B-RSES was entered in all 12 hierarchical regressions in step 2. $\Delta R^{2}: R^{2}$-change. $\Delta F: F$-value for $R^{2}$-change. $\beta_{1}$ : standardized regression coefficient of self-esteem measure entered in step 1 (see column 1); $\beta_{2}$ : standardized regression coefficient of the B-RSES

$* p<.05, * * p<.01, * * * p<.001$

metric, and scalar invariance. Configural invariance tests whether the factorial structure is invariant across group, metric invariance whether the loadings are invariant, and scalar invariance whether the intercepts are invariant (cf. Milfont \& Fischer, 2010). Specifically, we tested whether the model fit would systematically decrease if, for example, loadings were constrained to be equal across groups (to test for measurement invariance). If the model fit would remain very similar $(\triangle \mathrm{CFI}<.01$ and $\triangle \mathrm{RMSEA}<$ .015; Chen, 2007), we would conclude that constraining the loadings has little impact and conclude that metric invariance is achieved.

To test for measurement invariance, we collapsed the data across all four samples (412 men, 1037 women, median age $=21$ years). For age, we performed a median split to obtain a group of younger $\left(M_{\mathrm{age}}=19.34\right.$ years, $\left.S D=1.07\right)$ and a group of older participants $\left(M_{\text {age }}=31.07\right.$ years, $\left.S D=9.97\right)$.

Table 6 shows that full invariance was established across age and gender, suggesting that women and men as well as younger and older people can be meaningfully compared. In other words, constraining loadings and intercepts had very little impact on the model fit (e.g., $\triangle \mathrm{CFI}<.01$; Chen, 2007). Consequently, the internal consistencies of the B-RSES were very similar across groups: $\alpha=.87$, for younger people, $\alpha=.89$ for older people, $\alpha=.89$ for women, and $\alpha=.88$ for men, with $\alpha=.89$ for the overall sample.

\section{General Discussion}

Self-esteem predicts a series of outcomes (Freire \& Tavares, 2011), and is one of the most widely studied constructs in social sciences (Bleidorn et al., 2016). The 
Table 6 Measurement invariance of the Brief-Rosenberg Self-esteem Scale across Age groups and Gender

\begin{tabular}{lllllll}
\hline & Models of invariance & CFI & RMSEA & $\Delta$ CFI & $\Delta$ RMSEA \\
\hline Age & Configural & .949 & .168 & - & & \\
Younger people $(n=752)$, older people $(n=695)$ & Metric & .949 & .142 & .000 & .026 \\
& Scalar & .942 & .134 & .007 & .008 \\
Gender & Configural & .951 & .168 & - & \\
Men $(n=412)$, women $(n=1037)$ & Metric & .950 & .143 & .001 & .025 \\
& Scalar & .946 & .131 & .004 & .012 \\
\hline
\end{tabular}

Note. $\mathrm{CFI}=$ comparative fit index; RMSEA = root mean square error of approximation. $\Delta=$ differences between the current and the previous model

Rosenberg Self-Esteem Scale is the main instrument for its assessment: It is used in almost half of the empirical studies published in major scientific journals that assessed self-esteem (Donnellan et al., 2015).

In line with previous research, we found support for the unidimensionality of the 10item version of the RSES (e.g., Gnambs et al., 2018; Gnambs \& Schroeders, 2017). As our sample consisted mainly of people with a higher education level $(78 \%$ with completed or incomplete higher education), the wording effect of the items disappeared (Gnambs \& Schroeders, 2017). Regarding the individual parameters of the items, we found that, in general, they had very high discrimination levels (Baker, 2001), that is an adequate ability to differentiate people according to the magnitude of self-esteem they present. Also, we found that the items are easily endorsed. Previous studies indicate that participants tend to score above the midpoint of the scale (Baumeister et al., 1989).

Based on the Item Response Theory results, we selected the five most informative items to compose the short version of the RSES (named Brief Rosenberg Self-Esteem Scale, BRSES). The unidimensional structure of the B-RSES was supported through Confirmatory Factor Analysis (Hu \& Bentler, 1999; Kline, 2015). Its items maintained excellent indicators of discrimination and accuracy, losing little psychometric information (Baker, 2001). In addition, both RSES and B-RSES had almost the same pattern of correlations with the Big Five personality traits. Also, the abbreviated version was strongly correlated with the five other RSES items that were not selected for its short version, indicating strong evidence of construct validity (Pasquali, 2010). Furthermore, B-RSES correlated strongly with three other measures of self-esteem, providing further support of its construct validity. More importantly however, it was as or more strongly associated with four dependent variables than three other short measures of self-esteem. Finally, the B-RSES is invariant across age and gender, suggesting that meaningful comparisons between those groups are possible.

The B-RSES also contains two reversed coded items that enable acquiescence control (Valentini, 2017; Valentini \& Hauck Filho, 2020), and cover the two subcomponents of global self-esteem (i.e., self-competence and self-acceptance; Schmitt \& Allik, 2005; Tafarodi \& Milne, 2002). As discussed above, people tend to respond more positively to positive items of self-esteem measures (DiStefano et al., 2012). Therefore, it is essential to control for this bias of acquiescence, being necessary to include negative items so that such positive assessment of the self is not overestimated due to a methodological effect. Indeed, the practice to select only positive items to increase reliability has repeatedly been criticized as negatively impacting the validity of 
scales (Clifton, 2020). Together, this reinforces the quality of the B-RSES in comparison to other short instruments that are more susceptible to items' compliance bias.

\section{Limitations and Final Considerations}

Despite the promising results, it is important to interpret them with caution. For instance, despite being a large sample, it is non-probabilistic and mostly made up of people with higher levels of education. Negative items are interpreted differently by people with lower cognitive abilities and in future studies it is important to test whether such a bias affects the structure of B-RSES, as it does for the long version of the measure (Gnambs et al., 2018; Gnambs \& Schroeders, 2017; Lima \& Souza, 2019).

In conceptual and methodological terms, the present research provides a psychometrically adequate measure that, although short, covers important aspects of selfesteem which are not part in the single item self-esteem scale (SISE) or the very homogeneous Lifespan Self-Esteem Scale (LSES). In addition, the B-RSES reduces the impact of response bias by including reversed coded items, unlike some other selfesteem scales (e.g., SISE, GSES). Long and short scales do usually not differ due to the ability to predict external criteria (Kemper et al., 2019). In this sense, we observed that shortening the RSES by $50 \%$ resulted in almost identical correlation coefficient of selfesteem with other variables. This indicates that B-RSES can replace RSES in research on self-esteem, especially in contexts in which rapid assessment and the use of multiple scales is required. In sum, Concise measures are crucial, because they allow rapid application which also saves money if participants are paid.

\section{Declarations}

Ethical Approval All procedures performed in studies involving human participants were in accordance with the ethical standards of the institutional and/or national research committee and with the 1964 Helsinki declaration and its later amendments or comparable ethical standards.

Informed Consent was obtained from all individual participants included in the study.

Conflict of Interest On behalf of all authors, the corresponding author states that there is no conflict of interest.

\section{Appendix}

The 5-items of the Brief Rosenberg Self-Esteem Scale

01. At times I think I am no good at all.

02. All in all, I am inclined to think that I am a failure

03. I feel I do have much to be proud of.

04. On the whole, I am satisfied with myself.

05. I take a positive attitude toward myself.

First two items need to be recoded before averaged with the other three items. Note that in the original scale, item 3 is also recoded ("I feel I do not have much to be proud of"). 
However, in the Brazilian 10-item version of the RSES (Sbicigo et al. 2010), which we used as a basis to develop our short version, item 3 was not recoded. We do not expect the results to be dependent on whether item 3 is recoded or not.

Open Access This article is licensed under a Creative Commons Attribution 4.0 International License, which permits use, sharing, adaptation, distribution and reproduction in any medium or format, as long as you give appropriate credit to the original author(s) and the source, provide a link to the Creative Commons licence, and indicate if changes were made. The images or other third party material in this article are included in the article's Creative Commons licence, unless indicated otherwise in a credit line to the material. If material is not included in the article's Creative Commons licence and your intended use is not permitted by statutory regulation or exceeds the permitted use, you will need to obtain permission directly from the copyright holder. To view a copy of this licence, visit http://creativecommons.org/licenses/by/4.0/.

\section{References}

Appel, M., Gnambs, T., \& Maio, G, R. (2012). A short measure of the need for affect. Journal of Personality Assessment, 94, 418-426. https://doi.org/10.1080/00223891.2012.666921.

Baker, F, B. (2001). The basics of item response theory. ERIC

Bakker, B, N., \& Lelkes, Y. (2018). Selling ourselves short? How abbreviated measures of personality change the way we think about personality and politics. The Journal of Politics, 80, 1311-1325. https://doi.org/ 10.1086/07616.

Baldasaro, R, E., Shanahan, M, J., \& Bauer, D, J. (2013). Psychometric properties of the mini-IPIP in a large, nationally representative sample of young adults. Journal of Personality Assessment, 95, 74-84. https:// doi.org/10.1080/00223891.2012.700466.

Baumeister, R, F., Tice, D, M., \& Hutton, D, G. (1989). Self-presentational motivations and personality differences in self-esteem. Journal of Personality, 57, 547-579. https://doi.org/10.1111/j.1467-6494.1989. tb02384.x

Bleidorn, W., Buyukcan-Tetik, A., Schwaba, T., Van Scheppingen, M, A., Denissen, J, J., \& Finkenauer, C. (2016). Stability and change in self-esteem during the transition to parenthood. Social Psychological and Personality Science, 7, 560-569. https://doi.org/10.1177/1948550616646428.

Chalmers, R, P. (2012). MIRT: A multidimensional item response theory package for the R environment. Journal of Statistical Software, 48, 1-29. https://doi.org/10.18637/jss.v048.i06.

Chen, F, F. (2007). Sensitivity of goodness of fit indexes to lack of measurement invariance. Structural Equation Modeling: A Multidisciplinary Journal, 14(3), 464-504. https://doi.org/10.1080/ 10705510701301834.

Clifton, J, D, W. (2020). Managing validity versus reliability trade-offs in scale-building decisions. Psychological Methods, 25(3), 259-270. https://doi.org/10.1037/met0000236.

Coelho, G, L, H., Hanel, P, H., \& Wolf, L, J. (2020). The very efficient assessment of need for cognition: Developing a six-item version. Assessment, 27(8), 1870-1885. https://doi.org/10.1177/ 1073191118793208.

Cooper, A, J., Smillie, L, D., \& Corr, P, J. (2010). A confirmatory factor analysis of the mini-IPIP five-factor model personality scale. Personality and Individual Differences, 48, 688-691. https://doi.org/10.1016/j. paid.2010.01.004.

Davidov, E., Meuleman, B., Cieciuch, J., Schmidt, P., \& Billiet, J. (2014). Measurement equivalence in crossnational research. Annual Review of Sociology, 40(1), 55-75. https://doi.org/10.1146/annurev-soc071913-043137.

Diener, E., \& Diener, M. (1995). Cross-cultural correlates of life satisfaction and self-esteem. Journal of Personality and Social Psychology, 68, 653-663. https://doi.org/10.1037/0022-3514.68.4.653.

DiStefano C., Morgan G, B., \& Motl R, W. (2012). An examination of personality characteristics related to acquiescence. Journal of Applied Measurement, 13,41-56. Retrieved from https://europepmc.org/article/ $\mathrm{med} / 22677496$ 
Donnellan, M, B., Oswald, F, L., Baird, B, M., \& Lucas, R, E. (2006). The mini-IPIP scales: Tiny-yeteffective measures of the big five factors of personality. Psychological Assessment, 18, 192-203. https:// doi.org/10.1037/1040-3590.18.2.192.

Donnellan, M, B., Trzesniewski, K, H., \& Robins, R, W. (2015). Measures of self-esteem. In G. J. Boyle, D. H. Saklofske, \& G. Matthews (Eds.), Measures of personality and social psychological constructs (pp. 131-157). Elsevier. https://doi.org/10.1016/B978-0-12-386915-9.00006-1.

Freire, T., \& Tavares, D. (2011). Influência da autoestima, da regulação emocional e do gênero no bem-estar subjetivo e psicológico de adolescentes. Archives of Clinical Psychiatry, 38, 184-188. https://doi.org/10. 1590/S0101-60832011000500003.

García, J, A., y Olmos, F, C., Matheu, M, L., \& Carreño, T, P. (2019). Self-esteem levels vs global scores on the Rosenberg self-esteem scale. Heliyon, 5, e01378. https://doi.org/10.1016/j.heliyon.2019.e01378.

Gnambs, T., \& Schroeders, U. (2017). Cognitive abilities explain wording effects in the Rosenberg self-esteem scale. Assessment, 27, 404-418. https://doi.org/10.1177/1073191117746503.

Gnambs, T., Scharl, A., \& Schroeders, U. (2018). The structure of the Rosenberg self-esteem scale. Zeitschrift für Psychologie, 226, 14-29. https://doi.org/10.1027/2151-2604/a000317.

Góngora, V, C., \& Casullo, M, M. (2009). Validación de la escala de autoestima de Rosenberg en población general y en población clínica de la Ciudad de Buenos Aires. Revista Iberoamericana de Diagnóstico y Evaluación-e Avaliação Psicológica, 1, 179-194. Retrieved from https://www.redalyc.org/pdf/4596/ 459645443010.pdf

Gosling, S, D., Rentfrow, P, J., \& Swann Jr, W, B. (2003). A very brief measure of the big-five personality domains. Journal of Research in Personality, 37, 504-528. https://doi.org/10.1016/S0092-6566(03) 00046-1.

Gray-Little, B., Williams, V, S., \& Hancock, T, D. (1997). An item response theory analysis of the Rosenberg self-esteem scale. Personality and Social Psychology Bulletin, 23, 443-451. https://doi.org/10.1177/ 0146167297235001.

Harris, M, A., Donnellan, M, B., \& Trzesniewski, K, H. (2018). The lifespan self-esteem scale: Initial validation of a new measure of global self-esteem. Journal of Personality Assessment, 100, 84-95. https://doi.org/10.1080/00223891.2016.1278380.

Hu, L, T., \& Bentler, P, M. (1999). Cutoff criteria for fit indexes in covariance structure analysis: Conventional criteria versus new alternatives. Structural Equation Modeling: A Multidisciplinary Journal, 6, 1-55. https://doi.org/10.1080/10705519909540118.

Hutz, C, S. (2000). Adaptação da escala de autoestima de Rosenberg. Manuscrito não publicado. Universidade Federal do Rio Grande do Sul

Hutz, C, S., \& Zanon, C. (2011). Revisão da adaptação, validação e normatização da escala de autoestima de Rosenberg. Avaliação Psicológica, 10, 41-49. Retrieved from http://pepsic.bvsalud.org/pdf/avp/v10n1/ v10n1a05.pdf

Iannaccone, M., D'Olimpio, F., Cella, S., \& Cotrufo, P. (2016). Self-esteem, body shame and eating disorder risk in obese and normal weight adolescents: A mediation model. Eating Behaviors, 21, 80-83. https:// doi.org/10.1016/j.eatbeh.2015.12.010.

Kemper, C, J., Trapp, S., Kathmann, N., Samuel, D, B., \& Ziegler, M. (2019). Short versus long scales in clinical assessment: Exploring the trade-off between resources saved and psychometric quality lost using two measures of obsessive-compulsive symptoms. Assessment, 26, 767-782. https://doi.org/10.1177/ 1073191118810057.

Kline, R, B. (2015). Principles and practice of structural equation modeling (4th ed.). The Guilford Press.

Konstabel, K., Lönnqvist, J, E., Leikas, S., García Velázquez, R., Qin, H., Verkasalo, M., \& Walkowitz, G. (2017). Measuring single constructs by single items: Constructing an even shorter version of the "short five" personality inventory. PLoS One, 12, e0182714. https://doi.org/10.1371/journal.pone.0182714.

Lima, T, J, S, D., \& Souza, L, E, C, D. (2019). Rosenberg self-esteem scale: Method effect and gender invariance. Psico-USF, 24, 517-528. https://doi.org/10.1590/1413-82712019240309.

Lorenzo-Seva, U., \& Ferrando, P, J. (2013). Factor 9.2: A comprehensive program for fitting exploratory and semiconfirmatory factor analysis and IRT models. Applied Psychological Measurement, 37, 497-498. https://doi.org/10.1177/0146621613487794.

Lorenzo-Seva, U., Timmerman, M, E., \& Kiers, H, A, L. (2011) The Hull method for selecting the number of common factors. Journal Multivariate Behavioral Research, 46, 340-364. https://doi.org/10.1080/ 00273171.2011 .564527 .

Martín-Albo, J., Núñez, J, L., Navarro, J, G., \& Grijalvo, F. (2007). The Rosenberg self-esteem scale: Translation and validation in university students. The Spanish Journal of Psychology, 10, 458-467. https://doi.org/10.1017/S1138741600006727. 
Milfont, T, L., \& Fischer, R. (2010). Testing measurement invariance across groups: Applications in crosscultural research. International Journal of Psychological Research, 3(1), 111-121

Mimura, C., \& Griffiths, P. (2007). A Japanese version of the Rosenberg self-esteem scale: Translation and equivalence assessment. Journal of Psychosomatic Research, 62, 589-594. https://doi.org/10.1016/j. jpsychores.2006.11.004.

Pasquali L. (2010). Instrumentação Psicológica: Fundamentos e práticas. Artmed

Pimentel, C, E., Silva, F, M, D, S, M., Santos, J, L, F, D., Oliveira, K, G., Freitas, N, B, C., Couto, R, N., \& Brito, T, R, D, S. (2018). Single-Item Self-Esteem Scale: Adaptação brasileira, relações com personalidade e comportamentos pró-sociais. Psico-USF, 23(1), 1-11. https://doi.org/10.1590/1413-82712018230101.

Rajlic, G., Kwon, J, Y., Roded, K., \& Hubley, A, M. (2019). Development of the global self-esteem measure: A pilot study. Journal of Psychoeducational Assessment, 37, 863-873. https://doi.org/10.1177/0734282918801816.

Rammstedt, B., \& Beierlein, C. (2014). Can't we make it any shorter?. Journal of Individual Differences, 35, 212-220. https://doi.org/10.1027/1614-0001/a000141.

R Core Team (2020). R: A language and environment for statistical computing. R Foundation for Statistical Computing, Vienna, Austria. URL https://www.R-project.org/

Robins, R, W., Hendin, H, M., \& Trzesniewski, K, H. (2001). Measuring global self-esteem: Construct validation of a single-item measure and the Rosenberg self-esteem scale. Personality and Social Psychology Bulletin, 27, 151-161. https://doi.org/10.1177/0146167201272002.

Rosenberg, M. (1965). Society and the adolescent self-image. Princeton University Press

Rosseel, Y. (2012). Lavaan: An R package for structural equation modeling and more. Version $0.5-12$ (BETA). Journal of Statistical Software, 48, 1-36. Retrieved from http://users.ugent.be/ yrosseel/ lavaan/lavaanIntroduction.pdf

Salmela-Aro, K., \& Nurmi, J, E. (2007). Self-esteem during university studies predicts career characteristics 10 years later. Journal of Vocational Behavior, 70, 463-477. https://doi.org/10.1016/j.jvb.2007.01.006

Samejima, F. (1969). Estimation of latent ability using a response pattern of graded scores1. ETS Research Bulletin Series, 1968(1), i-169. https://doi.org/10.1002/j.2333-8504.1968.tb00153.x.

Sbicigo, J, B., Bandeira, D, R., \& Dell'Aglio, D, D. (2010). Escala de Autoestima de Rosenberg (EAR): Validade fatorial e consistência interna. Psico-USF, 15, 395-403. https://doi.org/10.1590/S1413-82712010000300012.

Schmitt, D, P., \& Allik, J. (2005). Simultaneous administration of the Rosenberg self-esteem scale in 53 nations: Exploring the universal and culture-specific features of global self-esteem. Journal of Personality and Social Psychology, 89, 623-642. https://doi.org/10.1037/0022-3514.89.4.623

Segabinazi, J, D., Zortea, M., Zanon, C., Bandeira, D, R., Giacomoni, C, H., \& Hutz, C, S. (2012). Escala de afetos positivos e negativos para adolescentes: Adaptação, normatização e evidências de validade. Avaliação Psicológica, 11, 1-12. Retrieved from https://www.redalyc.org/pdf/3350/335027499002.pdf

Sinclair, S, J., Blais, M, A., Gansler, D, A., Sandberg, E., Bistis, K., \& LoCicero, A. (2010). Psychometric properties of the Rosenberg self-esteem scale: Overall and across demographic groups living within the United States. Evaluation \& the Health Professions, 33, 56-80. https://doi.org/10.1177/0163278709356187.

Sowislo, J, F., \& Orth, U. (2013). Does low self-esteem predict depression and anxiety? A meta-analysis of longitudinal studies. Psychological Bulletin, 139, 213-240. https://doi.org/10.1037/a0028931

Steiger, A, E., Allemand, M., Robins, R, W., \& Fend, H, A. (2014). Low and decreasing self-esteem during adolescence predict adult depression two decades later. Journal of Personality and Social Psychology, 106, 325-338. https://doi.org/10.1037/a0035133.

Tafarodi, R, W., \& Milne, A, B. (2002). Decomposing global self-esteem. Journal of Personality, 70, 443484. https://doi.org/10.1111/1467-6494.05017.

Tafarodi, R, W., \& Swann Jr., W, B. (2001). Two-dimensional self-esteem: Theory and measurement. Personality and Individual Differences, 31, 653-673. https://doi.org/10.1016/S0191-8869(00)00169-0.

Valentini, F. (2017). Influência e controle da aquiescência na análise fatorial. Avaliação Psicológica, 16. Retrieved from https://www.redalyc.org/pdf/3350/335053541001.pdf

Valentini, F., \& Hauck Filho, N. (2020). O impacto da aquiescência na estimação de coeficientes de validade. Avaliação Psicológica, 19, 1-3. https://doi.org/10.15689/ap.2020.1901.ed.

Ziegler, M., Kemper, C, J., \& Kruyen, P. (2014). Short scales-five misunderstandings and ways to overcome them. Journal of Individual Differences, 35, 185-189. https://doi.org/10.1027/1614-0001/a000148

Publisher's Note Springer Nature remains neutral with regard to jurisdictional claims in published maps and institutional affiliations. 